Article

\title{
Pharmacokinetics and Tissue Distribution Study of Caudatin in Normal and Diethylnitrosamine-Induced Hepatocellular Carcinoma Model Rats
}

\author{
Yunru Peng * and Yongfang Ding
}

Department of Pharmacology and Toxicology, Jiangsu Provincial Institute of Traditional Chinese Medicine, 100 Shizi Street, Nanjing 210028, China; E-Mail: angelding9@hotmail.com

* Author to whom correspondence should be addressed; E-Mail: pengyunru@126.com; Tel: +86-25-52362105; Fax: +86-25-85637817.

Academic Editor: Jean Jacques Vanden Eynde

Received: 17 November 2014 / Accepted: 26 February 2015 / Published: 5 March 2015

\begin{abstract}
Caudatin is a potential antitumor agent isolated from the traditional Chinese medicine "baishouwu", which was the root tuber of Cynanchum auriculatum Royle ex Wight. In our previous studies, caudatin showed selectivity on human hepatoma cell line SMMC7721 among several different tumor cell lines, and further in vivo tests validated the inhibitory action of caudatin against hepatic cancer using an $\mathrm{H}_{22}$ solid tumor model in mice, but to our knowledge, the biopharmaceutical properties of caudatin are largely unknown. In this study, a simple, rapid and sensitive ultra-performance liquid chromatography-tandem mass spectrometry (UPLC-MS/MS) method for the determination of caudatin in rat plasma and tissues, which kept the run time to detect one sample within 4 min, was developed and validated. Pharmacokinetics and tissue distribution studies of caudatin in conventional rats and hepatocellular carcinoma (HCC) model rats were then conducted for the first time. Statistically significant differences were observed between conventional rats and diethylnitrosamine (DEN)-induced $\mathrm{HCC}$ rats with respect to pharmacokinetic parameters, including maximum concentration $\left(\mathrm{C}_{\max }\right)$, time to reach $\mathrm{C}_{\max }\left(T_{\max }\right)$, half-life $\left(t_{1 / 2}\right)$, area under the concentration-time curve $\left(\mathrm{AUC}_{0-\mathrm{t}}, \mathrm{AUC}_{0-\infty}\right)$, mean residence time $\left(\mathrm{MRT}_{0-\mathrm{t}}\right.$ and $\left.\mathrm{MRT}_{0-\infty}\right)$, and oral clearance $(\mathrm{CL} / \mathrm{F})$. Increased exposures of caudatin were found in the plasma and livers of HCC model rats, which would be helpful for a better understanding of pharmacological effect of caudatin in treating HCC disease.
\end{abstract}


Keywords: pharmacokinetics; C-21 steroidal glycoside; Cynanchum auriculatum Royle ex wight; caudatin; hepatocellular carcinoma

\section{Introduction}

Hepatocellular carcinoma (HCC) is one of the most common cancers, associated with high mortality, and the world's highest morbidity and mortality rates for this malignant tumor are found in China [1]. Since HCC mostly arises from chronic hepatitis and liver cirrhosis caused by infection with hepatitis $\mathrm{C}$ virus (HCV) or hepatitis B virus (HBV), novel antihepatocarcinogenic agents exhibiting comprehensive effects in therapy of chronic hepatitis and prevention liver cirrhosis are required [2].

The root of Cynanchum auriculatum Royle ex Wight, known as "baishouwu" in China, has been widely used in the clinic as a beneficial and tonic agent for long times. Its major active components, C-21 steroidal glycosides, are of considerable interest because of their bioactivities, including prevention and therapy of chronic hepatitis [3], hepatic fibrosis [4] and liver cancer [5-7]. In our previous studies, several C-21 steroidal glycosides were isolated from baishouwu, of which caudatin was the most potent compound against tumor cell lines and showed selectivity on human hepatoma cell line SMMC7721 among several different tumor cell lines [8]. On account of the results, we speculated that the C-21 steroidal glycosides obtained in our work were sensitive to some human tumor cell lines such as liver cancer cell lines. The in vivo assays further showed that caudatin significantly inhibited the growth of transplantable $\mathrm{H}_{22}$ tumors in mice [8]. Further in vitro studies illustrated that the anticancer activity of caudatin could be attributed partly to its inhibition of cell proliferation and induction of apoptosis in human hepatoma cell line SMMC7721 through caspase activation [9]. Recent studies also proved that caudatin could induce cell cycle arrest and caspase-dependent apoptosis in HepG2 cells [10]. Interestingly, caudatin derivatives were recently reported to exhibit potent anti-HBV activity and could be developed as novel anti-HBV agents $[11,12]$, from which we hypothesized that the mechanism of caudatin for treating hepatocellular carcinoma was comprehensive. As a potential inhibitor of liver cancer, the biopharmaceutical properties of caudatin are largely unknown, so in our previous study an oral pharmacokinetic evaluation of caudatin in rats was conducted, which revealed a non-linear profile between 10 and $40 \mathrm{mg} / \mathrm{kg}$ [13]. Up to now, the pharmacokinetics of caudatin in hepatocellular carcinoma model animals remains unclear. Considering the anti-hepatocarcinogenic effect of caudatin, it is important to compare the differences of its pharmacokinetics and distribution in conventional and hepatocellular carcinoma model animals.

Therefore, in the present study a comparative investigation of the pharmacokinetics and tissue distribution of caudatin in conventional and DEN-induced hepatocellular carcinoma model rats was conducted. In our previous studies, a novel liquid chromatography/electrospray ionization-tandem mass spectrometry (LC/ESI-MS/MS) method in positive multiple reaction monitoring (MRM) mode was developed for the determination of caudatin in rat plasma [14]. Owing to the progress of the apparatus, a more efficient, sensitive rapid resolution liquid chromatography/tandem mass spectrometry (UPLC-MS/MS) method for the determination of caudatin in rat plasma and different tissues had been developed and validated in this study, which purpose was to evaluate the pharmacokinetics and tissue 
distribution of caudatin in conventional and DEN-induced hepatocellular carcinoma model rats. To the best of our knowledge, no studies have provided unequivocal evidence on the pharmacokinetic properties of caudatin in hepatocellular carcinoma model rats.

\section{Results and Discussion}

\subsection{Method Development}

In this study, mass spectrometry (MS) detecting conditions were operated according to the MS signal response of the target compound and the results indicated that the negative mode was much more sensitive than the positive mode for both caudatin and the internal standard (IS). In order to achieve good resolution, symmetric peak shapes for caudatin and IS and a short run time, the chromatographic conditions were optimized through several trials. Finally, a Waters ACQUITY ${ }^{\mathrm{TM}}$ UPLC $^{\mathrm{TM}}$ BEH C18 column $(100 \times 2.1 \mathrm{~mm}, 1.7 \mu \mathrm{m})$ was used for the chromatographic separation. It was found that a mixture of $0.1 \%$ formic acid and acetonitrile could achieve our purpose and was finally adopted as the mobile phase for the chromatographic separation.

\subsection{Method Validation}

The detection of caudatin and IS by MRM was highly selective with no interference. Typical chromatograms of blank plasma or tissue homogenate, blank plasma or tissue homogenate spiked with caudatin and IS, samples from rats after oral administration at a dose of $20 \mathrm{mg} / \mathrm{kg}$ are presented in Figure 1. The retention times were $1.49 \mathrm{~min}$ for caudatin, $1.26 \mathrm{~min}$ for IS. The MS spectra of caudatin and IS were monitored in negative ion mode and $[\mathrm{M}-\mathrm{H}]^{-}$ions were observed as the predominant ions for both of them.

Standard curves prepared for caudatin in plasma and tissue homogenates showed good linearity over the concentration ranges of $5-1000 \mathrm{ng} / \mathrm{mL}$ and the lower limit of quantification was $5 \mathrm{ng} / \mathrm{mL}$. The lower limit of detection was $1.2 \mathrm{ng} / \mathrm{mL}$.

The accuracy and precision of the method were evaluated based on the data from the quality control (QC) plasma and liver tissue homogenate samples at three concentrations (10, 100 and $800 \mathrm{ng} / \mathrm{mL})$ in three validation runs. As shown in Table 1, the results of the tested samples were all within the acceptable criteria (relative standard deviation (RSD) $\%<15 \%$; accuracy error (RE) \% less than $\pm 15 \%$ ), indicating the acceptable accuracy and precision of the method developed.

The extraction recoveries of caudatin from rat plasma and tissue homogenate samples were all more than $75.0 \%$ at different concentration levels (Table 1) and the extraction recovery of IS was more than $75.0 \%$, which indicated that the recoveries of caudatin and IS were consistent, precise and reproducible at different concentration levels.

The possibility of matrix effect caused by ionization competition between the analytes and the endogenous co-eluents was evaluated at three concentrations in six replicates. No significant matrix effect was observed for the analyte in the samples.

The measured concentration of caudatin at each QC level deviated within 15.0\%, which demonstrated that they were stable in plasma and tissue homogenate samples at room temperature for $48 \mathrm{~h}$, at $-20{ }^{\circ} \mathrm{C}$ for at least 30 days and after three freeze and thaw cyles (Table 2). 
A
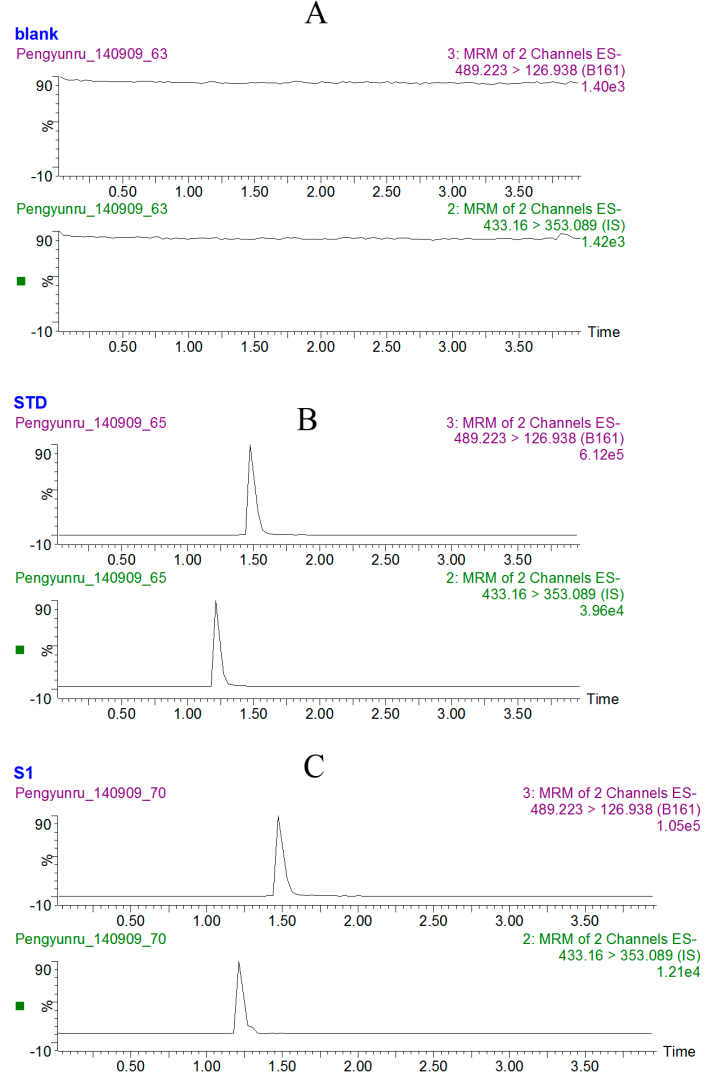

$\mathrm{D}$

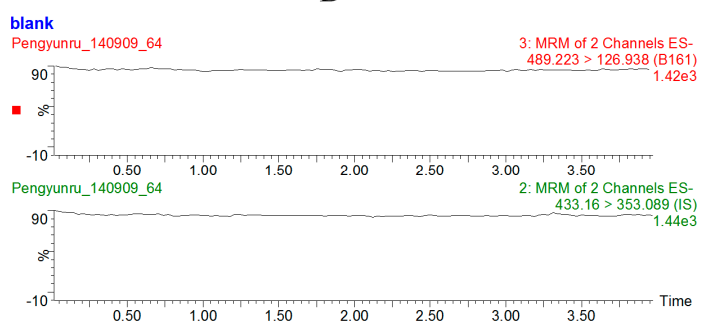

$\mathrm{E}$

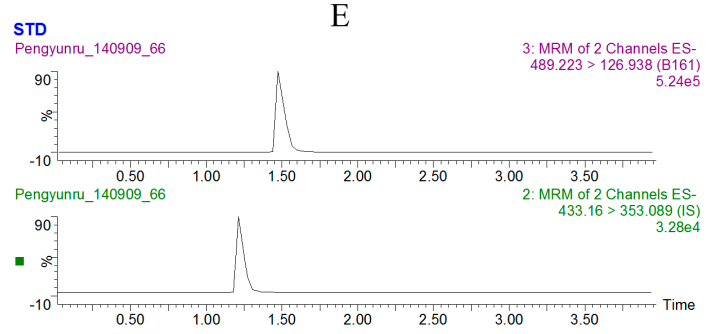

F

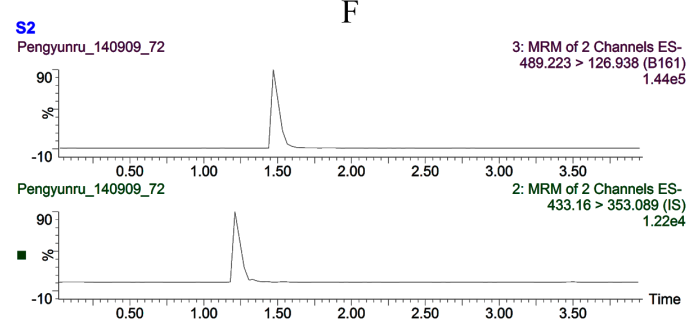

Figure 1. Typical chromatograms of caudatin. (A) blank plasma; (B) blank plasma spiked with caudatin and IS; (C) $0.5 \mathrm{~h}$ plasma sample after administration of caudatin at a dose of $20 \mathrm{mg} / \mathrm{kg}$; (D) blank liver tissue homogenate; (E) blank liver tissue homogenate spiked with caudatin and IS; (F) $0.5 \mathrm{~h}$ liver homogenate sample after administration of caudatin at a dose of $20 \mathrm{mg} / \mathrm{kg}$.

Table 1. Accuracy, precision and recovery of caudatin in rat plasma and tissue homogenate $(\mathrm{n}=5)$.

\begin{tabular}{cccccc}
\hline & $\begin{array}{c}\text { Concentration } \\
(\mathbf{n g} / \mathbf{m L})\end{array}$ & $\begin{array}{c}\text { Intra-day } \\
\text { R.S.D. }\end{array}$ & $\begin{array}{c}\text { Inter-day } \\
\text { R.S.D. }(\%)\end{array}$ & $\begin{array}{c}\text { Accuracy } \\
\text { R.E. }(\%)\end{array}$ & $\begin{array}{c}\text { Recovery } \\
(\mathbf{\%})\end{array}$ \\
\hline \multirow{3}{*}{ plasma } & 10 & 9.5 & 9.2 & 6.6 & 95.6 \\
& 100 & 6.8 & 8.4 & -5.5 & 96.8 \\
& 800 & 7.6 & 6.5 & 8.7 & 92.4 \\
\hline \multirow{2}{*}{ tissue } & 10 & 6.9 & 7.7 & -8.9 & 99.3 \\
homogenate & 100 & 8.7 & 9.4 & 7.1 & 91.1 \\
& 800 & 8.6 & 9.5 & 5.5 & 93.1 \\
\hline
\end{tabular}

\subsection{Method Application}

\subsubsection{Pharmacokinetic Study}

Pharmacokinetic studies were performed in conventional rats and DEN-induced HCC rats after a single dose of caudatin at $20 \mathrm{mg} / \mathrm{kg}$ to show the applicability of the validated UPLC-MS/MS method. 
The mean plasma concentration-time profiles were shown in Figure 2. The selected pharmacokinetic parameters are listed in Table 3.

Table 2. Stability of caudatin in rat plasma and tissue homogenate $(n=5)$.

\begin{tabular}{|c|c|c|c|c|}
\hline & Stability & $\begin{array}{c}\text { Added C } \\
(\mathrm{ng} / \mathrm{mL})\end{array}$ & $\begin{array}{r}\text { Found C } \\
(\mathrm{ng} / \mathrm{mL})\end{array}$ & $\begin{array}{c}\text { Accuracy R.E. } \\
(\%) \\
\end{array}$ \\
\hline \multirow{9}{*}{ plasma } & \multirow[t]{3}{*}{$48 \mathrm{~h}$ at room temperature } & 10 & 9.1 & -9.0 \\
\hline & & 100 & 95.7 & -4.3 \\
\hline & & 800 & 789.4 & -1.3 \\
\hline & \multirow[t]{3}{*}{1 month at $-20^{\circ} \mathrm{C}$} & 10 & 9.6 & -4.0 \\
\hline & & 100 & 96.2 & -3.8 \\
\hline & & 800 & 814.2 & 1.8 \\
\hline & \multirow[t]{3}{*}{ three freeze-thaw cycles } & 10 & 10.4 & 4.0 \\
\hline & & 100 & 94.2 & -5.8 \\
\hline & & 800 & 759.1 & -5.1 \\
\hline \multirow{9}{*}{$\begin{array}{c}\text { tissue } \\
\text { homogenate }\end{array}$} & \multirow[t]{3}{*}{$48 \mathrm{~h}$ at room temperature } & 10 & 10.3 & 3.0 \\
\hline & & 100 & 92.3 & -7.7 \\
\hline & & 800 & 745.5 & -6.8 \\
\hline & \multirow[t]{3}{*}{1 month at $-20^{\circ} \mathrm{C}$} & 10 & 9.2 & -8.0 \\
\hline & & 100 & 93.2 & -6.8 \\
\hline & & 800 & 736.6 & -7.9 \\
\hline & \multirow[t]{3}{*}{ three freeze-thaw cycles } & 10 & 9.4 & -6.0 \\
\hline & & 100 & 105.4 & 5.4 \\
\hline & & 800 & 857.3 & 7.2 \\
\hline
\end{tabular}

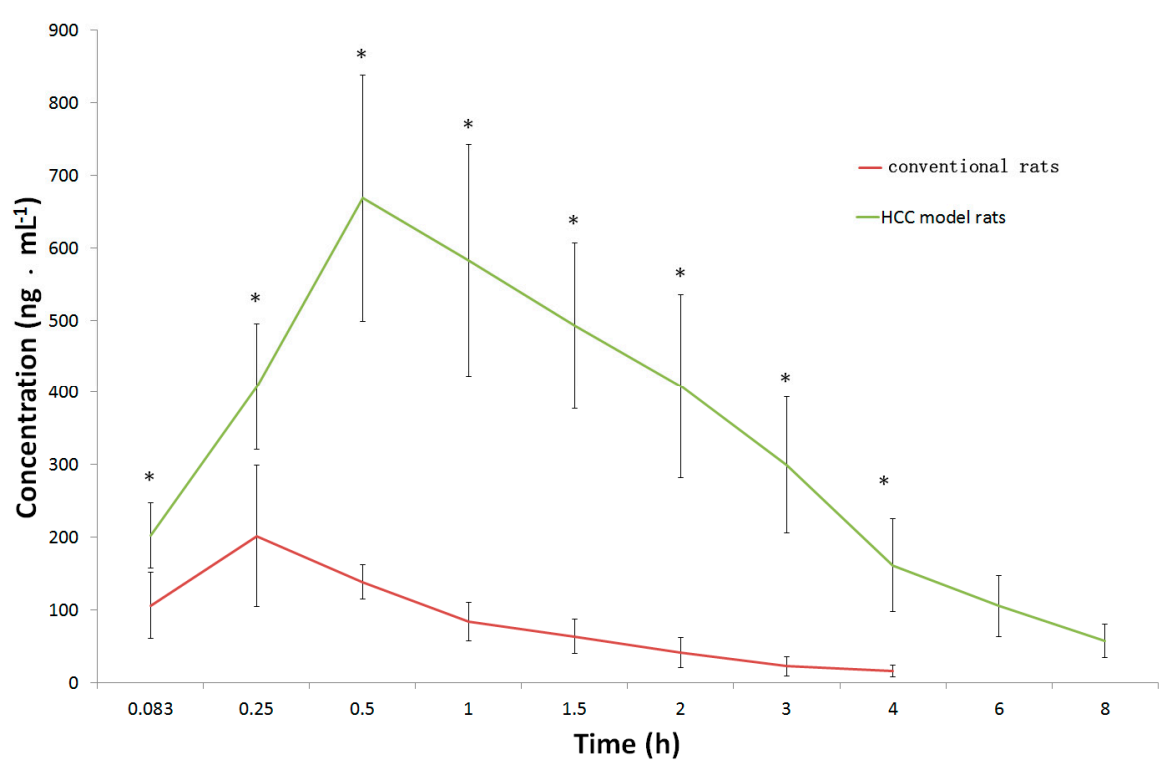

Figure 2. Mean plasma concentration-time profiles of caudatin after oral administration at a dose of $20 \mathrm{mg} / \mathrm{kg}$ in conventional and HCC rats. Significantly different from the conventional rats $(*, p<0.05)$. 
Table 3. Pharmacokinetic parameters of caudatin in conventional and HCC model rats after oral administration at a dose of $20 \mathrm{mg} / \mathrm{kg}(\mathrm{n}=6)$.

\begin{tabular}{cccc}
\hline Parameter & Unit & Conventional Rats & HCC Model Rats \\
\hline $\mathrm{AUC}(0-\mathrm{t})$ & $\mu \mathrm{g} \cdot \mathrm{h} / \mathrm{L}$ & $236.8 \pm 62.8$ & $2006.0 \pm 334.1^{*}$ \\
$\mathrm{AUC}(0-\infty)$ & $\mu \mathrm{g} \cdot \mathrm{h} / \mathrm{L}$ & $263.4 \pm 76.2$ & $2251.9 \pm 386.0^{*}$ \\
$\mathrm{MRT}(0-\mathrm{t})$ & $\mathrm{h}$ & $1.21 \pm 0.13$ & $2.47 \pm 0.32^{*}$ \\
$\mathrm{MRT}(0-\infty)$ & $\mathrm{h}$ & $1.68 \pm 0.39$ & $3.62 \pm 1.11^{*}$ \\
$\mathrm{~T}_{1 / 2 z}$ & $\mathrm{~h}$ & $1.25 \pm 0.49$ & $2.89 \pm 1.78^{*}$ \\
$\mathrm{~T}_{\max }$ & $\mathrm{h}$ & $0.29 \pm 0.10$ & $1.00 \pm 0.45^{*}$ \\
$\mathrm{C}_{\max }$ & $\mu \mathrm{g} / \mathrm{L}$ & $314.7 \pm 82.0$ & $713.4 \pm 129.3 *$ \\
$\mathrm{CLz} / \mathrm{F}$ & $\mathrm{L} / \mathrm{h} / \mathrm{kg}$ & $80.8 \pm 20.8$ & $9.13 \pm 1.75^{*}$ \\
$\mathrm{Vz} / \mathrm{F}$ & $\mathrm{L} / \mathrm{kg}$ & $147.7 \pm 78.0$ & $37.2 \pm 21.2 *$ \\
\hline \multicolumn{4}{c}{$*<0.05$, compared with the conventional rats. }
\end{tabular}

Caudatin was rapidly absorbed in conventional rats, and its high concentration level could only be detected at $0.29 \pm 0.10 \mathrm{~h}$ after oral administration. The plasma maximum concentration $\left(\mathrm{C}_{\max }\right)$ and area under the concentration-time curve $\left(\mathrm{AUC}_{0-\mathrm{t}}\right)$ of caudatin after oral administration to conventional rats were $314.7 \pm 82.0 \mu \mathrm{g} / \mathrm{L}$ and $236.8 \pm 62.8 \mu \mathrm{g} \cdot \mathrm{h} / \mathrm{L}$, respectively. Statistically significant differences were observed between conventional rats and DEN-induced HCC rats with respect to pharmacokinetic parameters including $\mathrm{C}_{\max }, T_{\max }, t_{1 / 2}, \mathrm{AUC}_{0-\mathrm{t}}, \mathrm{AUC}_{0-\infty}$, mean residence time ( $\mathrm{MRT}_{0-\mathrm{t}}$ and $\mathrm{MRT}_{0-\infty}$ ), and oral clearance (CL/F). Compared with conventional rats, the HCC conditions induced 2.31-, 3.45-, 2.27and 8.47-fold increases in elimination half-life $\left(t_{1 / 2}\right), T_{\max }, \mathrm{C}_{\max }$ and $\mathrm{AUC}_{0-\mathrm{t}}$ for caudatin, respectively. $\mathrm{Vz} / \mathrm{F}$ and $\mathrm{CL} / \mathrm{F}$ values for caudatin in conventional rats were increased 3.97- and 8.85-fold, compared with the corresponding parameters observed in HCC rats. The result indicated that caudatin was eliminated rapidly in blood circulation in conventional rats. The HCC conditions could remarkably increase the blood concentration of caudain and prolong its retention in blood.

In the present study, large differences in all measured PK parameters for caudatin between the conventional and $\mathrm{HCC}$ model rats were found and exposure of caudatin in the plasma of HCC rats was increased obviously with $\mathrm{C}_{\max }$ and AUC values being increased 2.27- and 8.47-fold, respectively, compared with those in conventional rats. This difference in oral bioavailability of caudatin in conventional and HCC model rats may due to some reason such as drug metabolism. Several reports have indicated that the enzymes involved in phase I and phase II metabolism underwent apparent changes in patients with hepatocellular carcinoma [15-18], which could impact drug metabolism, disposition and pharmacotherapy. Moreover, animal experiments also proved that there were obvious differences in drug metabolism between the normal rats and the diethylnitrosamine-induced HCC model rats $[19,20]$. Perhaps we could presume that the changes in the metabolism in HCC rats might partially explain the different pharmacokinetic behaviors of caudatin among normal and model rats. Further studies are needed to better understand the mechanism of this difference.

\subsubsection{Tissue Distribution Study}

The profile of caudatin in tissue homogenate (heart, liver, spleen, lung, kidney, brain, stomach, small intestine, rectum, testis, muscle and fat) after oral administration of caudatin at $0.5 \mathrm{~h}, 1.0 \mathrm{~h}$ and $3.0 \mathrm{~h}$ is 
shown in Figure 3. According to the time process of distribution, caudatin was observed in most tissues just $0.5 \mathrm{~h}$ after oral administration. At this moment, caudatin was concentrated in the digestive system, especially in the stomach and small intestine, which showed the main tissue absorption. Compared with conventional rats, the HCC conditions significantly increased concentrations of caudatin in heart, liver, spleen, kidney, testis and fat, especially in liver (Table 4). The concentrations of caudatin found in livers exceeded those observed in other tissues at three sampling-time points, aside from the digestive system. The result revealed significant tissue targeting of caudatin after oral administration.
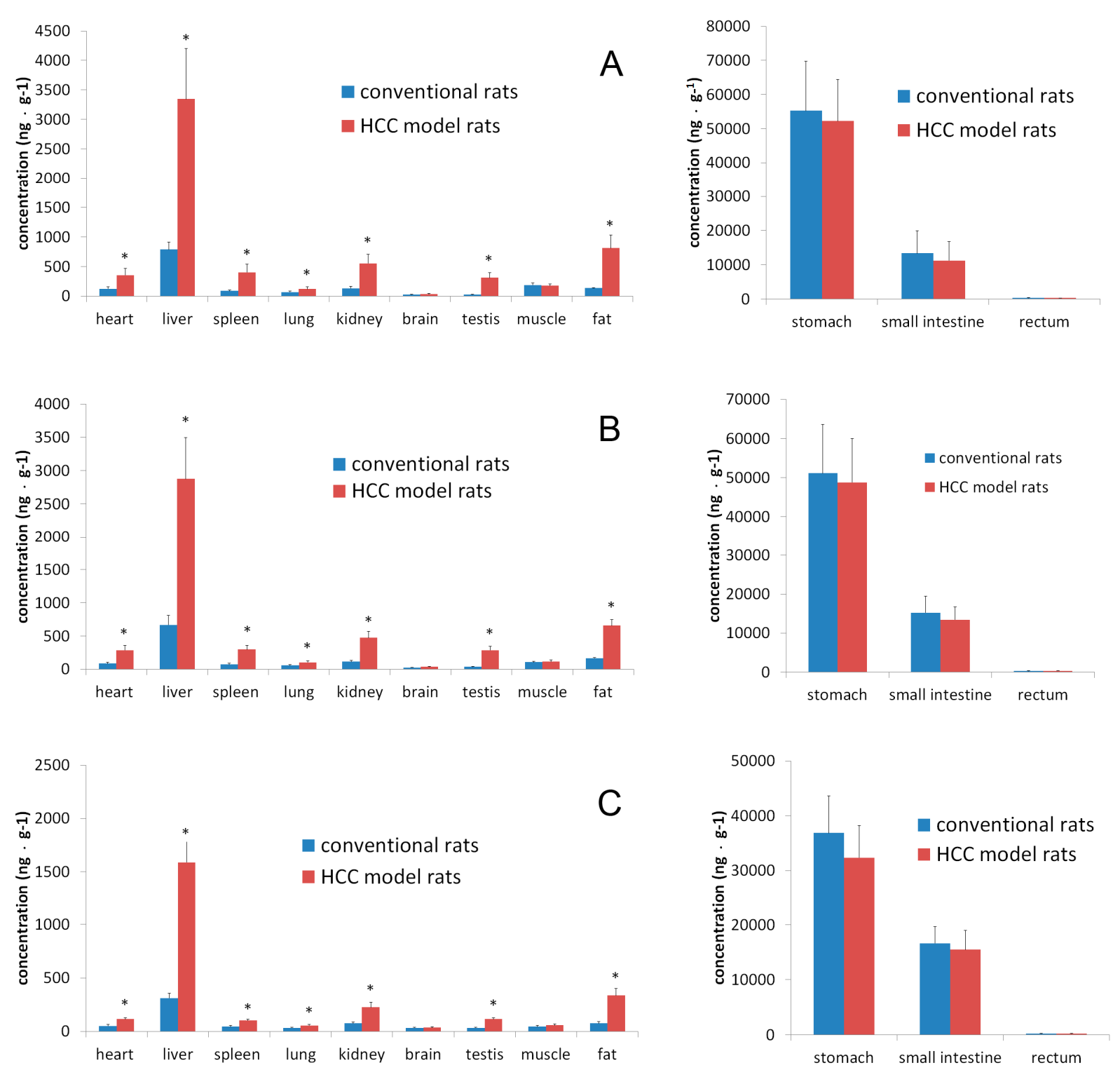

Figure 3. The concentration of caudatin in tissues after oral administration at a dose of $20 \mathrm{mg} / \mathrm{kg}$ in conventional and HCC rats. (A) $0.5 \mathrm{~h}$; (B) $1.0 \mathrm{~h}$; (C) $3.0 \mathrm{~h}$. Significantly different from the conventional rats $(*, p<0.05)$. 
Table 4. Fold increase in plasma or tissues of caudatin in HCC model rats vs conventional rats $(n=5)$.

\begin{tabular}{cccc}
\hline \multirow{2}{*}{ Plasma or Tissues } & \multicolumn{3}{c}{ Fold Increase } \\
\cline { 2 - 4 } & $\mathbf{0 . 5} \mathbf{~}$ & $\mathbf{1 . 0} \mathbf{~ h}$ & $\mathbf{3 . 0} \mathbf{~ h}$ \\
\hline plasma & 4.83 & 6.95 & 13.36 \\
heart & 2.91 & 3.37 & 2.23 \\
liver & 4.26 & 4.30 & 5.10 \\
spleen & 4.63 & 4.26 & 2.31 \\
lung & 1.83 & 1.82 & 1.65 \\
kidney & 4.18 & 4.19 & 3.05 \\
brain & 1.48 & 1.56 & 1.05 \\
testis & 13.89 & 7.90 & 3.38 \\
muscle & 0.94 & 1.09 & 1.30 \\
fat & 5.95 & 3.96 & 4.46 \\
stomach & 0.95 & 0.95 & 0.88 \\
small intestine & 0.84 & 0.88 & 0.93 \\
rectum & 0.97 & 1.06 & 0.93 \\
\hline
\end{tabular}

\section{Experimental}

\subsection{Materials, Reagents and Animals}

Caudatin (98.6\% purity) was isolated from the root tubers of $C$. auriculatum according to the previously reported protocols [8]. The internal standard, dexamethasone acetate $(99.2 \%$ purity, 100122-201206), was obtained from the National Institute for the Control of Pharmaceutical and Biological Products (Beijing, China). The structures of caudatin and IS are displayed in Figure 4. HPLC grade acetonitrile and methanol were purchased from Merck (Darmstadt, Germany). Deionized water was purified by a Milli-Q system (Millipore, Bedford, MA, USA). All the other reagents were of analytical grade.
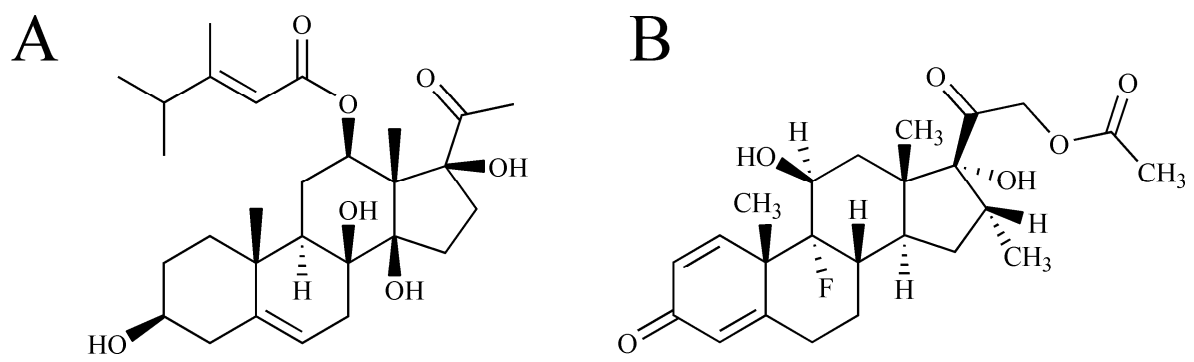

Figure 4. The chemical structures of caudatin (A) and dexamethasone acetate (B).

Male Sprague-Dawley rats (180-200 g) were provided by Shanghai SLAC Laboratory Animal Co. (Shanghai, China). Animals were maintained in an environmentally controlled room under controlled temperature $\left(22-24{ }^{\circ} \mathrm{C}\right)$ and relative humidity $(40 \%-70 \%)$ with a 12-h light/dark cycle. The animal care, use, and experimental protocols were approved by the animal care committee of Jiangsu Provincial Institute of Traditional Chinese Medicine. 
Fifty-two male Sprague-Dawley rats were randomly divided into hepatocellular carcinoma (HCC) model group $(\mathrm{n}=30)$ and normal control group $(\mathrm{n}=22)$. Diethylnitrosamine $(10 \mathrm{mg} / \mathrm{kg})$ was orally administered to rats of model group five times a week for 14 weeks, and the normal control group received vehicle [21]. At the end of 16th week, blood samples were collected via the angular vein for liver function test for all animals and one rat in each group was randomly sacrificed and liver tissue was stained with hematoxylin-eosin (HE) and Masson for histopathologic examination (Figure 5). Macroscopic and microscopic features of the liver were evaluated, which showed that the HCC model of rats had been established. The experiments were performed at the end of 16 th week since administration.

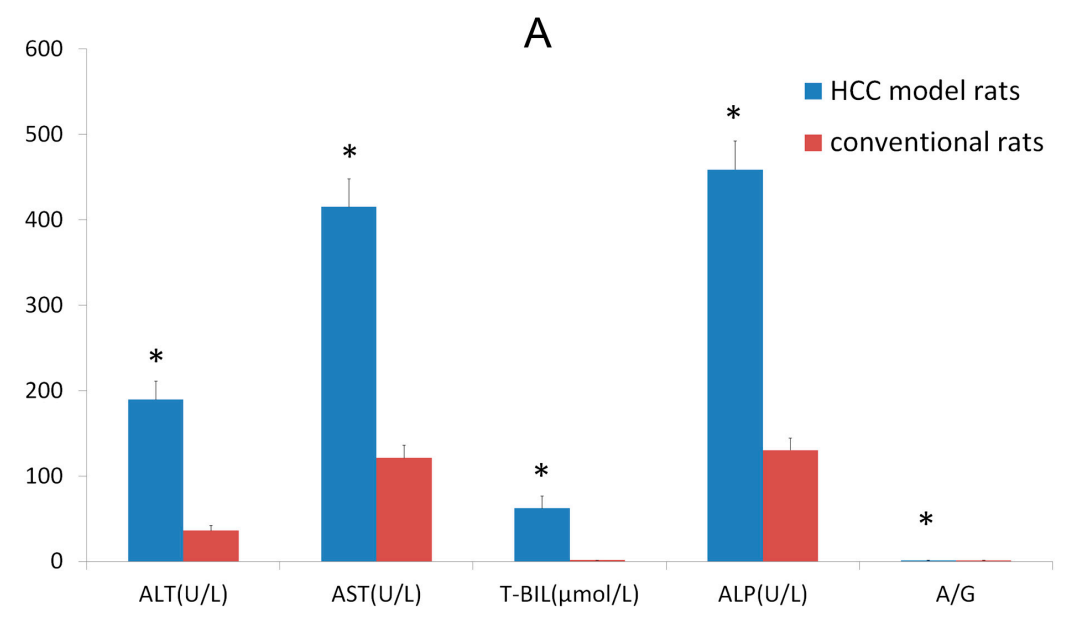

B
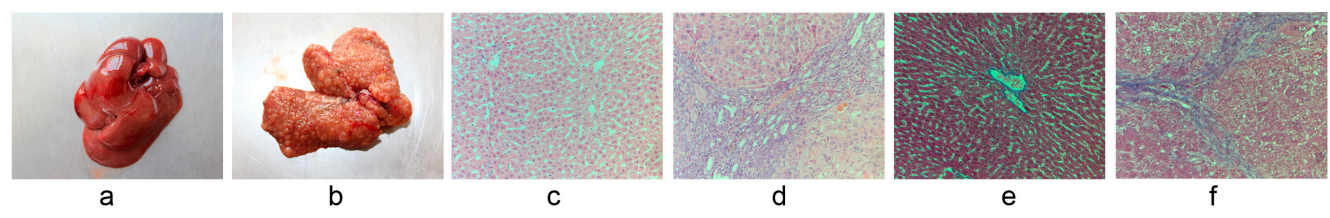

Figure 5. The represent of biochemistry parameters and histological evaluation in HCC model rats. (A) Biochemistry parameters of liver function; Significantly different from the conventional rats $(*, p<0.05)$. (B) Representative photographs. Macroscopic findings in liver of conventional (a) and HCC model rats (b). Histopathologic examination (HE staining, $\times 200)$ in liver of conventional $(\mathbf{c})$ and HCC model rats $(\mathbf{d})$. Masson staining $(\times 200)$ for liver of conventional (e) and HCC model rats (f).

\subsection{Instrumentation and Conditions}

The analysis of plasma and tissue samples was conducted on a Waters Acquity UPLC system (Waters, Milford, MA, USA), consisting of a binary solvent delivery system and an autosampler. UPLC separation was achieved on a Waters ACQUITY ${ }^{\mathrm{TM}}$ UPLC $^{\mathrm{TM}}$ BEH C18 column $(100 \times 2.1 \mathrm{~mm}, 1.7 \mu \mathrm{m})$ with gradient elution of $0.10 \%$ formic acid (A) and acetonitrile (B) at a flow rate of $0.4 \mathrm{~mL} / \mathrm{min}$, and column temperature $35{ }^{\circ} \mathrm{C}$. The gradient program was as follows: $0-2 \mathrm{~min}, 50 \%-95 \% \mathrm{~B} ; 2-3 \mathrm{~min}$, $95 \%-95 \% \mathrm{~B}$. The injection volume was $2 \mu \mathrm{L}$ and the total time needed to analyze one sample only is 4 min. All the analyses were operated using MassLynx XS Software. A Waters Corp. eXevo Triple 
Quadrupole MS equipped with an electrospray ionization (ESI) source was used for mass spectrometry detection. The parameters in the source were set as follows: capillary voltage, $3.0 \mathrm{kV}$; desolvation gas rate, $1,000 \mathrm{~L} / \mathrm{h}$; desolvation temperature, $500{ }^{\circ} \mathrm{C}$; cone gas flow rate, $50 \mathrm{~L} / \mathrm{h}$; source temperature $150{ }^{\circ} \mathrm{C}$. The analyte detection was performed by using the multiple reaction monitoring (MRM) technique.

\subsection{Standard Solution and Quality Control Samples}

The stock solution of caudatin was prepared by dissolving $10.0 \mathrm{mg}$ accurately weighed standard compound in $10.0 \mathrm{~mL}$ methanol to produce a concentration of $1.0 \mathrm{mg} / \mathrm{mL}$, and was stored at $4{ }^{\circ} \mathrm{C}$. A series of working solutions of caudatin were prepared freshly in methanol by diluting the stock solution in appropriate ratios at seven concentrations of 5-1000 $\mathrm{ng} / \mathrm{mL}$ for plasma or tissue samples. A stock solution of dexamethasone acetate $(1 \mathrm{mg} / \mathrm{mL})$ was prepared in methanol, from which a $4000 \mathrm{ng} / \mathrm{mL}$ internal standard (IS) working solution was prepared in methanol as well and stored at $4{ }^{\circ} \mathrm{C}$. Three concentration levels of quality control samples (QCs) were prepared containing caudatin (10, 100 and $800 \mathrm{ng} / \mathrm{mL})$ and IS (400 $\mathrm{ng} / \mathrm{mL})$ in the same manner.

\subsection{Sample Preparation}

All samples, QCs, and standards with a sample volume of $90 \mu \mathrm{L}$ spiked with $10 \mu \mathrm{L}$ of IS working solution were extracted with $1.5 \mathrm{~mL}$ of ethyl acetate. The mixture was vortexed for $2 \mathrm{~min}$ and centrifuged at $4000 \mathrm{r} / \mathrm{min}$ for $5 \mathrm{~min}$. The supernatant was pipetted into a $2 \mathrm{~mL}$ glass test tube and evaporated at $60{ }^{\circ} \mathrm{C}$ under nitrogen. The residue was reconstituted with $150 \mu \mathrm{L}$ of mobile phase and followed by vortexing for $1 \mathrm{~min}$ and centrifuged at $4000 \mathrm{r} / \mathrm{min}$ for $5 \mathrm{~min}$. The samples were transferred into autosampler vials with inner bracing tubes for analysis, respectively.

\subsection{Method Validation}

The method was validated for accuracy, precision, selectivity, calibration curve range, and reproducibility over a concentration range of 5-1000 $\mathrm{ng} / \mathrm{mL}$ using three calibration standards, and five replicates of QC samples at each concentration level in three separate runs. The lower limit of quantification (LLOQ) for caudatin in plasma was defined as the lowest concentration, linear with the calibration curves having a relative error (RE\%) below $20 \%$ and accuracy between $80 \%$ and $120 \%$. The lower limit of detection (LLOD on column) was defined as the amount that could be detected with a signal-to-noise ratio of 3 .

The precision and accuracy of the entire method were assessed at three QC concentration levels (10, $100,800 \mathrm{ng} / \mathrm{mL}$ ), each extracted and analyzed in five replicates on the same day (intra-day precision and accuracy) and on three consecutive days (inter-day precision and accuracy). Precision was defined as the relative standard deviation (RSD) and accuracy was calculated as the relative difference between calculated and nominal concentration of the QC samples (bias). The intra- and inter-day precision and bias were set at $\leq 15 \%$.

The extraction recoveries of caudatin were calculated by comparing the peak-area ratios (caudatin/IS) of extracted plasma standards to the peak-area ratios of post-extraction plasma blanks spiked at corresponding concentrations. The recovery experiments were performed with three QC concentrations 
$(10,100,800 \mathrm{ng} / \mathrm{mL})$, with five replicates at each concentration. The matrix effect was investigated by extracting "blank" normal plasma and reconstituting with methanol containing a known amount of the analytes, analyzing the reconstituted extracts, and then comparing the peak areas of the analytes with that of analytes in methanol.

Sample stability was determined by analyzing QC samples stored for $48 \mathrm{~h}$ at room temperature, 1 month at $-20^{\circ} \mathrm{C}$ and subjected to three freeze-thaw cycles. For each of the storage conditions, five replicates were analyzed at three concentration levels.

\subsection{Application to Pharmacokinetics and Tissue Distributions}

After the histopathologic examination showed the HCC model of rats had been established, 21 rats were selected randomly from HCC model group (six rats died in model development) for pharmacokinetic and distribution studies. The rats were divided into two groups: 21 conventional rats in group A and $21 \mathrm{DEN}$-induced HCC rats in group B, with six rats per group for blood withdrawn and 15 rats for getting tissue samples. The animals were deprived of food for $12 \mathrm{~h}$ with water before the experiment and received an oral administration at dose of $20 \mathrm{mg} / \mathrm{kg}$. Blood samples (about $250 \mu \mathrm{L}$ ) were collected into heparinized Eppendorf tubes at 0, 0.083, 0.25, 0.5, 1, 1.5, 2, 3, 4, 6, $8 \mathrm{~h}$ after dosing. Then the blood samples were immediately centrifuged and kept frozen at $-20{ }^{\circ} \mathrm{C}$ until analysis. Five rats were decapitated, tissues including the heart, liver, spleen, lung, kidney, brain, stomach, small intestine, rectum, testis, muscle and fat were removed, washed of residual blood, and weighed at $0.5 \mathrm{~h}, 1.0 \mathrm{~h}, 3.0 \mathrm{~h}$ after drug administration. Each tissue sample was homogenized with deionized water $(1 \mathrm{~g}: 9 \mathrm{~mL})$, centrifuged and stored at $-20{ }^{\circ} \mathrm{C}$ until analysis. All pharmacokinetic parameters were processed by noncompartmental analysis using the DAS software. A two-tailed Student's $t$ test was used to compare the pharmacokinetic parameters between the conventional rats and model rats. $p \leq 0.05$ was considered statistically significant.

\section{Conclusions}

A simple, rapid and sensitive UPLC-MS/MS method was developed and validated for the determination of caudatin in rat plasma and tissues, which kept the run time to detect one sample under $4 \mathrm{~min}$. Pharmacokinetics and tissue distribution studies of caudatin in conventional rats and HCC model rats were conducted and the results indicated that the pharmacokinetic profiles and tissue distribution were statistically different. Increased exposures of caudatin were found in the plasma and livers of HCC model rats, which should be helpful for a better understanding of the pharmacological effect of caudatin in treating $\mathrm{HCC}$ disease.

\section{Acknowledgments}

This research was financially supported by the National Natural Science Foundation of China (No: 81102884, 81373888). 


\section{Author Contributions}

Participated in the research design: Yunru Peng and Yongfang Ding; Conducted experiments: Yunru Peng and Yongfang Ding; Performed data analyses: Yongfang Ding; Wrote the manuscript: Yunru Peng.

\section{Conflicts of Interest}

The authors declare no conflict of interest.

\section{References}

1. Center, M.M.; Jemal, A. International trends in liver cancer incidence rates. Cancer Epidemiol. Biomark. Prev. 2011, 20, 2362-2368.

2. El-Serag, H.B. Hepatocellular carcinoma. N. Engl. J. Med. 2011, 365, 1118-1127.

3. Yin, J.L.; Li, X.; Zhang, S.X.; Zhang, H.Q. Protective effect of $\mathrm{C}_{21}$ steroidal ester saponin of Cynanchum auriculatum royle ex wight on acute CCL4- induced liver injury in mice. Anhui Med. Pharm. J. 2007, 11, 198-200.

4. Lv, W.H.; Zhang, A.X.; Xu, S.; Zhang, H.Q. Effects of general glycosides in Cynanchum auriculatum of Jiangsu province on liver fibrosis of rats. China J. Chin. Mater. Med. 2009, 34, 2508-2511.

5. Wang, D.Y.; Zhang, H.Q.; Li, X. Apoptosis induced by the C21 sterols in Baishouwu and its mechanism of action in hepatoma. Acta Pharm. Sin. 2007, 42, 366-370.

6. Bi, F.; Tao, W.Y.; Lu, Z.M. Anti-tumor efficacy of the extract from Radix Cynanchi Auriculati on mouse liver cancer Hepatoma 22. Chin. Tradit. Pat. Med. 2007, 29, 1586-1590.

7. Bi, F.; Guo, W.J.; Tao, W.Y. Screening of bioactive substances from the root of Cynanchum Auriculatum Royle ex Wight by Anti-Liver Cancer Bel 7402 in vitro. J. Food Sci. Biotechnol. 2008, 27, 109-112.

8. Peng, Y.R.; Li, Y.B.; Liu, X.D.; Zhang, J.F.; Duan, J.A. Antitumor activity of C-21 steroidal glycosides from Cynanchum auriculatum Royle ex Wight. Phytomedicine 2008, 15, 1016-1020.

9. Peng, Y.R.; Li, Y.B.; Liu, X.D.; Zhang, J.F.; Duan, J.A. Apoptosis induced by caudatin in human hepatoma cell line SMMC7721. Chin. J. Nat. Med. 2008, 6, 210-213.

10. Fei, H.R.; Chen, H.L.; Xiao, T.; Chen, G.; Wang, F.Z. Caudatin induces cell cycle arrest and caspase- dependent apoptosis in HepG2 cell. Mol. Biol. Rep. 2012, 39, 131-138.

11. Wang, L.J.; Geng, C.A.; Ma, Y.B.; Luo, J.; Huang, X.Y.; Chen, H.; Zhou, N.J.; Zang, X.M.; Chen, J.J. Design, synthesis and molecular hybrids of caudatin and cinnamic acids as novel anti- hepatitis B virus agents. Eur. J. Med. Chem. 2012, 54, 352-365.

12. Wang, L.J.; Geng, C.A.; Ma, Y.B.; Huang, X.Y.; Luo, J.; Chen, H.; Guo, R.H.; Zhang X.M.; Chen, J.J. Synthesis, structure- activity relationships and biological evaluation of caudatin derivatives as novel anti- hepatitis B virus agents. Bioorg. Med. Chem. 2012, 20, 2877-2888.

13. Peng, Y.R.; Wang, D.W.; Ding, Y.F.; Luo, Y.H.; Li, Y.B.; Liu, X.D. Oral pharmacokinetics of Caudatin in rats. Chin. J. Nat. Med. 2010, 8, 471-473.

14. Wang, D.W.; Peng, Y.R.; Li, Y.B.; Qian, S.H.; Wu, J.; Zhang, J. Study on determination of caudatin in rat plasma by LC-MS-MS. Chin. Pharm. J. 2008, 43, 704-706. 
15. Yan, T.; Gao, S.; Peng, X.; Shi, J.; Xie, C.; Li, Q.; Lu, L.; Wang, Y.; Zhou, F.; Liu, Z.; et al. Significantly decreased and more variable expression of major CYPs and UGTs in liver microsomes prepared from HBV-positive human hepatocellular carcinoma and matched pericarcinomatous tissues determined using an isotope label-free UPLC-MS/MS method. Pharm. Res. 2015, 32, 1141-1157.

16. Fukuda, H.; Ebara, M.; Okuyama, M.; Sugiura, N.; Yoshikawa, M.; Saisho, H.; Shimizu, R.; Motoji, N.; Shigematsu, A.; Watayo, T. Increased metabolizing activities of the tricarboxylic acid cycle and decreased drug metabolism in hepatocellular carcinoma. Carcinogenesis 2002, 23, 2019-2023.

17. Fritz, P.; Behrle, E.; Beaune, P.; Eichelbaum, M.; Kroemer, H.K. Differential expression of drug metabolizing enzymes in primary and secondary liver neoplasm: Immunohistochemical characterization of cytochrome P4503A and glutathione-S-transferase. Histochemistry 1993, 99, 443-451.

18. Ye, L.; Yang, X.S.; Guo, E.S.; Chen, W.Y.; Lu, L.L.; Wang, Y.; Peng, X.J.; Yan, T.M.; Zhou, F.Y.; Liu, Z.Q. Sorafenib metabolism is significantly altered in the liver tumor tissue of hepatocellular carcinoma patient. PLoS One 2014, 9, e96664.

19. Liu, Y.F.; Zha, B.S.; Zhang, H.L.; Zhu, X.J.; Li, Y.H.; Zhu, L.; Guan, X.H.; Feng, Z.Q.; Zhang, J.P. Characteristic gene expression profiles in the progression from liver cirrhosis to carcinoma induced by diethylnitrosamine in a rat mode. J. Exp. Clin. Cancer Res. 2009, 28, 107-122.

20. Bishayee, A.; Roy, S.; Chatterjee, M. Characterization of selective induction and alteration of xenobiotic biotransforming enzymes by vanadium during diethylnitrosamine-induced chemical rat liver carcinogenesis. Oncol. Res. 1999, 11, 41-53.

21. Rui, W.J.; He, S.F.; Huang, X.J. ; Fang, Z.; Hang, X.; Li, Q.J.; Hu, M.; Yang, Y. Expression of pSmad3L and PAI-1 during the process of DEN-induced hepatic fibrosis-carcinoma in rats. Chin. Pharmacol. Bull. 2012, 28, 1393-1397.

Sample Availability: Samples of the compound caudatin are available from the authors.

(C) 2015 by the authors; licensee MDPI, Basel, Switzerland. This article is an open access article distributed under the terms and conditions of the Creative Commons Attribution license (http://creativecommons.org/licenses/by/4.0/). 